\title{
JOHN PENDLEBURY (1904-1941): EL ENAMORADO DE CRETA
}

\author{
RicARdo H. ElÍA \\ Centro Islámico de la República Argentina
}

Resumen: John Pendlebury vivió apenas 37 primaveras. A los dos años perdió su ojo izquierdo en un accidente y desde entonces usó uno de cristal. A pesar de ello, fue arqueólogo, deportista, actor, héroe militar y ofrendó su vida por la libertad de Creta.

Palabras claves: Minoica - arqueología - filoheleno - paracaidista - resistencia.

\section{JOHN PENDLEBURY (1904-1941): THE ENAMOURED OF CRETE}

\begin{abstract}
John Pendlebury lived only 37 springs. When he was two years old he lost his left eye due to an accident and from that time on he always wore a glass one. Despite this, he was an archaeologist, sportsman, actor, military hero and offered his life for the freedom of Crete.
\end{abstract}

Key words: Minoan - archaeology - philhellene - paratrooper - resistance.

Recibido:10.03.2014 - Aceptado: 28.04.2014

\section{Correspondencia: Ricardo H. Elía.}

Ricardohselia@yahoo.com.ar Secretario de Cultura y Director del Departamento de Estudios Históricos del Centro Islámico de la República Argentina. Av. San Juan 3053 (1233) Buenos Aires, Argentina. Tel. (54-11) 4931-3577 (interno 113). 


\section{«... que se grabe con letras elegantes, Filoheleno» ${ }^{1}$.}

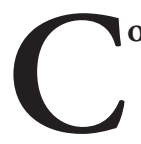

onstantino Cavafis

Se llamaba John Pendlebury. Vivió apenas 37 primaveras, si bien no llegó a cumplir los 37 años, y desde los dos su ojo izquierdo era de cristal debido a un accidente. A pesar de ello, fue arqueólogo, deportista, actor, héroe militar y mártir, pues dio su vida por la libertad de Creta.

En sus tiempos de Cambridge John fue un atleta que superó nada menos que al velocista Lord Burghley, identificado como Lord Lindsay en "Carrozas de Fuego" (1981).

En Egipto trabajó en el yacimiento de Tell El Amarna siguiendo los pasos de Sir William Matthew Flinders Petrie, y en Creta fue el heredero de Sir Arthur Evans en Cnosós. Al producirse en mayo de 1941 el asalto paracaidista nazi contra la isla, John colaboró activamente en la resistencia cretense. Herido en combate cerca de Heraklión, al perder su uniforme de oficial (tenía el grado de capitán) y sus placas de identificación, los invasores lo fusilaron. Sin embargo, para muchos, por una u otra razón, siguió con vida después de muerto.

Por entonces, la inteligencia de las SS se preguntaba: 'Wer war dieser Engländer' - ¿Quién era este inglés?

\section{Filohelenos}

Un fenómeno surgido a principios del siglo XIX fueron los románticos filohelenos. Además de franceses como el vizconde de Chateaubriand y Delacroix, y alemanes como Winckelmann y Hölderlin, entre muchos otros, fueron los británicos los que más se destacaron en defender el legado y la

${ }^{1}$ Miguel Castillo Didier (1991), Kavafis integro: Ensayo y traducción de su poesía. Santiago de Chile: Ed. Universitaria, Tomo I, p. 297. 
independencia de Grecia. Baste con nombrar a John Keats, Percy Bysshe Shelley, George Finlay y Lord Byron.

Nos dice Fotios Malleros ${ }^{2}$ que «En la época clásica, los términos filohelenismo y filohelenos se aplicaban a los griegos para significar su amor a la patria. [...] En tiempos del Renacimiento, se denominaban filohelenos a los admiradores y estudiosos de la antigüedad clásica griega. Pero el vocablo tomó un significado importante durante la revolución griega y, en especial, luego de la muerte de Lord Byron" ${ }^{3}$.

El escritor Oscar Wilde, interesado por la arqueología de Irlanda, llegó a la convicción de que los antiguos celtas y griegos compartieron un ideal común basado en la estética. ${ }^{4}$ Esa idea la reflejó en "Dorian Gray", y en "La importancia de llamarse Ernesto" donde hay una creativa relación con la "Ética” de Aristóteles, los "Diálogos" de Platón y las comedias de Menandro.

En el siglo XX tuvimos a los escritores Edward Morgan Forster (1879-1970) y a Lawrence Durrell (1912-1990). Ambos, por distintos motivos, interactuaron con la Alejandría de Cavafis. ${ }^{5}$ Tampoco deberíamos olvidar a Robert Graves (1895-1885), el autor de "El Conde Belisario" (1938), "El vellocino de oro" (1944), "La hija de Homero" (1955) y "Los mitos griegos" (1968).

Pero en John Pendlebury el filohelenismo tuvo una connotación muy singular. No solamente amó a Grecia sino que sucumbió combatiendo por ella como ningún otro extranjero lo había hecho antes.

\section{El "wikehamista”}

John Devitt Stringfellow Pendlebury nació en Londres el 12 de octubre de 1904. Su padre, Herbert Stringfellow ‘Pen’ Pendlebury (1870-1953), era cirujano

${ }^{2}$ Fotios Malleros Kasimatis (1914-1986), helenista e historiador griego nacido en una ciudad de la antigua Jonia, Esmirna (entonces el Imperio otomano, hoy Turquía). A partir de 1948 comienza sus cursos de lengua e historia en la Universidad de Chile. En 1951 editó "El Imperio Bizantino, 395-1204", primer manual de Historia Bizantina publicado en América Latina, reeditado en 1987 gracias al trabajo de dos de sus discípulos, Héctor Herrera y Alejandro Zorbás. En 1968 fundó el Centro de Estudios Griegos, Bizantinos y Neohelénicos que hoy lleva su nombre en la Universidad de Chile, instituto único en su género en Latinoamérica, siendo su actual Director el Profesor Miguel Castillo Didier, también formado por Fotios Malleros.

${ }^{3}$ Fotios Malleros en el prólogo de Miguel Castillo Didier (1971), Antología de la literatura neohelénica. I Poesía. Santiago de Chile: Coedición del Centro de Estudios Bizantinos y Neohelénicos de la Universidad de Chile y la Editorial Andrés Bello. p. 18, nota 15².

${ }^{4}$ Véase Iain Ross (2013), Oscar Wilde and Ancient Greece. Cambridge: Cambridge University Press.

${ }^{5}$ Véase Jane Lagoudis Pinchin (2004), Alejandria: Cavafis, Forster y Durrell. Granada: Editorial Almed. 
del Hospital St George’s (por entonces cerca de Hyde Park) y del Cuerpo Médico del Ejército Real (a partir de 1908). Su madre Lilian Dorothea 'Lily' Devitt (1871-1921) era la hija de Sir Thomas Lane Devitt, presidente de la compañía naviera Devitt and Moore y de Fanny Theodora Pye-Smith. John fue hijo único y no tuvo hermanos.

Cuando tenía dos años, a fines de 1906, estando al cuidado de un amigo mientras sus padres se encontraban ausentes, accidentalmente se clavó un lápiz o pluma de acero en su ojo izquierdo [aunque otras versiones indican que esto sucedió al cruzar un campo de espinos]. Como fuese, su ojo no pudo ser salvado y a partir de entonces usaría durante toda su vida un ojo protésico de cristal que generalmente pasaba inadvertido.

Como consecuencia del no uso de su ojo izquierdo, llevaba siempre su ceja derecha levantada, dándole una apariencia singular y distinguida.

La infancia y adolescencia de John fueron sumamente entretenidas y sus padres se preocuparon de que su formación fuese rigurosa y al mismo tiempo amena. En 1917, con 13 ańos, comenzó su preparación para ingresar en el prestigioso Colegio Winchester estudiando griego y latín clásicos. En marzo de 1918 logró aprobar el examen de ingreso y se convirtió en un "wikehamista"6.

En septiembre de 1921 falleció su madre. Por entonces, John leía los clásicos griegos en su lengua original y se cuenta que en una ocasión le contó a su padre la narración de la primera obra de la trilogía de la "Orestíada" de Esquilo, el "Agamenón", describiendo con gran énfasis y detalle la muerte del rey de Micenas a manos de su esposa Clitemnestra.

Al graduarse en 1923 poseía sólidos estudios en historia de Grecia y una pasión: la Egiptología. Ya un año antes, había participado del viaje de la Sociedad de Exploración de Egipto para entrar en contacto directo con el mundo de la arqueología. Fue un hecho auspicioso. En noviembre de ese año, Howard Carter (1874-1939) descubrió la tumba del joven faraón Tutankamón y John se sintió más que nunca inspirado para dedicarse a la Egiptología.

${ }^{6}$ Estudiante o graduado en el Winchester College (Winchester, Hampshire), por el nombre de su fundador, Guillermo de Wykeham (1320/1324 -1404), Obispo de Winchester y Canciller de Inglaterra. Es el único colegio inglés con más seiscientos años de historia ininterrumpida (1382-2014). 
En abril de 1923, John junto con su amigo James Cullen realizó un extenso periplo por Europa que finalizó con una extensa visita a Grecia. En la Escuela Británica de Arqueología de Atenas tuvo la oportunidad de conocer y tratar a Alan Wace ${ }^{7}$, de quien John dijo que "sabía absolutamente todo de todo". Wace, más tarde, reconocería el entusiasmo de John por la arqueología de la Edad del Bronce en el Egeo. "Era alguien que me impresionó por su ansiedad y el querer ver las cosas por sí mismo", diría. ${ }^{8}$

La más importante experiencia de este primer y multifacético contacto de John con Grecia fue su deleite por el paisaje, la gente y el idioma. Finalmente, este encantamiento se convertiría en un hechizo que lo atraparía por el resto de su vida.

En septiembre de 1923 John comenzó sus clases en la Universidad de Cambridge y, como por entonces allí no existía el departamento de Egiptología, concentró sus estudios históricos en el mundo greco-romano. En esa casa de altos estudios fundada en 1231 cerca del río Cam, John descolló en dos actividades no particularmente recomendadas para un ser humano que carece de visión en uno de sus ojos: el teatro y el deporte. En lo primero siempre fue un actor amateur, pero la actuación le trajo el hábito de disfrazarse y realizar todo tipo de atrevidas escenas y aventuras. Y hay que decir, por otra parte, que John Pendlebury siempre gozó de un espíritu notablemente carente de inhibiciones, aunque a primera vista parecía un tipo excéntrico e introvertido.

En lo segundo, destacó como corredor y saltador de altura. Siendo miembro del Achilles Club de Cambridge trabó amistad con Harold Abrahams ${ }^{9}$ y Lord Burghley ${ }^{10}$, que serían los campeones olímpicos de la carrera de 100 metros de París (1924) y la de 400 metros de Ámsterdam (1928) respectivamente.

${ }^{7}$ Alan John Bayard Wace (1879-1957 fue un arqueólogo británico y director de la British School de Atenas de 1914 a 1923. Entre sus proyectos de campo estaban los de Esparta, Micenas, Troya, Tesalia, Corinto y Alejandría. Junto al arqueólogo estadounidense Carl Blegen (18871971), famoso por su trabajo en Pilos y en Troya, Wace llevó a cabo importantes trabajos sobre el desciframiento de las tablillas escritas con escritura Lineal B. Véase A. J. B. Wace (1949), Mycenae, An Archaelogical History and Guide. Princeton University Press.

${ }^{8}$ Cfr. Alan J. B. Wace et al., "John Dewitt Stringfellow Pendlebury, 1938-9", The Annual of the British School of Athens, XXXIX, 1943.

${ }_{9}^{9}$ Harold Maurice Abrahams (1899-1978) fue campeón olímpico británico de los 100 metros lisos en los Juegos de París de 1924.

${ }^{10}$ David Burghley (1905-1981), sexto marqués de Exeter, ganador de la medalla de oro en los 400 metros con vallas en los Juegos Olímpicos de Ámsterdam de 1928. 
Baste decir que en una competición John venció a este último, que era alumno del Magdalene Collage, por unos pocos centímetros, luego de estar ambos cabeza a cabeza durante casi toda la carrera, lo que constituyó una verdadera hazaña ${ }^{11}$. John estuvo cerca de calificar para participar en los Juegos Olímpicos de Ámsterdam de 1928.

El gran momento en la vida de John sería desde fines de octubre de 1927 a septiembre de 1928. Al obtener una beca del Pembroke College de la Universidad de Cambridge para estudiar en la Escuela Británica de Atenas, luego de un viaje por Europa central y los Balcanes con otro de sus amigos, Pierson 'Bob' Dixon ${ }^{12}$, John arribó al puerto de Pireo el 15 de noviembre de 1927 y se alojó en la Escuela Británica de Arqueología de Atenas. Allí conocería a una compatriota arqueóloga, Hilda Winifred White (1891-1970), de 36 años, de la que quedaría rápidamente prendado. Junto con ella haría su primera visita a Creta en febrero de 1928 donde tendría la oportunidad de intimar con Sir Arthur Evans ${ }^{13}$ y su ayudante Duncan Mackenzie ${ }^{14}$ en Villa Ariadna ${ }^{15}$.

John y Hilda hacían una pareja estupenda. Tanto en el continente (Atenas, Argos o Meteora) como en Creta, los griegos los llamaban Kúpıos Ţov (Señor

${ }^{11}$ Imogen Grundon (2007), The Rash Adventurer: A Life of John Pendlebury. With a Foreword by Patrick Leigh Fermor. London: Libri Publications Limited, p. 20.

${ }^{12}$ Sir Pierson John 'Bob’ Dixon (1904-1965), diplomático británico.

${ }^{13}$ Sir Arthur Evans (1851-1941), arqueólogo inglés formado en la Universidad de Oxford, se hizo eco de las sospechas del arqueólogo alemán Heinrich Schliemann (1822-1890) respecto del emplazamiento del Palacio de Cnosós luego que aquel trató de excavar en el lugar hacia 1887 (ya había estado investigando en la isla en 1876). Previamente, en 1879, Minos Kalokairinos (1843-1903), un comerciante de aceites y jabones cretense, cónsul de Espańa ocasional en la isla y aficionado a la arqueología, había desenterrado algunas tinajas del enclave. A partir del 23 de marzo de 1900, Evans comenzó las excavaciones en el área de Cnosós, donde había adquirido una parcela. En 1906 la mayor parte del recinto estaba ya excavada. En colaboración con Duncan Mackenzie y John Pendlebury, Evans dedicó su vida y su fortuna a Cnosós. Vale la pena aquí señalar que el Palacio de Cnosos original data del año 2000 a. C. y fue destruido por un terremoto. El descubierto e investigado por Evans fue reconstruido hacia 1700 a. C.

${ }^{14}$ Duncan Mackenzie (1861-1934), arqueólogo escocés, trabajó con Evans durante 30 años. Debido al padecimiento de una progresiva enfermedad mental fue despedido de su trabajo y murió en Italia.

${ }^{15}$ Villa Ariadna fue construida en Cnosós por Arthur Evans poco después que descubrió el palacio minoico, cuando el sitio era su propiedad privada. La villa se convirtió en el hogar, a su vez, de John Pendlebury, que lo utilizó como base para sus excavaciones en Cnosós y sus exploraciones de la isla. Tras la muerte de Pendlebury a manos de invasores paracaidistas alemanes, Villa Ariadna fue elegida como residencia por el general Kreipe, que vivía allí cuando fue secuestrado por Patrick Leigh Fermor y su grupo de guerrilleros. Villa Ariadna está circundada por el único jardín de estilo eduardiano-griego existente, un gran oasis de flora cretense. El jardín ha sido completamente estudiado por la Escuela Británica de Arqueología, con la participación especial de arquitectos y agrónomos de Heraklión. 
John) y $\Delta \varepsilon \sigma \pi$ oıvís Xı $\lambda \delta \alpha$ (Señorita Hilda). Su curiosidad inagotable los llevó a recorrer la Creta occidental hasta Hierápetra (lit. "piedra sacra»), la ciudad más meridional de Grecia, llamada "la novia del mar de Libia". En la ruta encontraron la mítica Cueva de Diktea ${ }^{16}$, tan cara a la identidad cretense respecto del nacimiento y la infancia de Zeus. En el otońo boreal de 1928, John viajó a Egipto para trabajar en el yacimiento de Tell El Amarna ${ }^{17}$ a las órdenes de Henri Frankfort $^{18}$, y Hilda retornó a sus estudios en Atenas. Ella está reconocida entre las mujeres británicas que más excavaron en Grecia ${ }^{19}$.

\section{Entre Cnosós, Tell El Amarna, Bagdad y Damasco}

En 1930, a la edad de 25 años, tras unas vacaciones en Italia y enseñar a Hilda los misterios de la esgrima, John gozaba de una posición única y privilegiada en el mundo arqueológico del Mediterráneo oriental: simultáneamente ocupaba los cargos de Curador o comisario artístico de Cnosós (como heredero de Arthur Evans) y Director de las excavaciones de Tell el-Amarna (como sucesor de Henri "Hans" Frankfort).

John llevaría adelante la sabia decisión de trabajar en Egipto durante las temporadas de otoño e invierno y en Creta en primavera y verano. Esta interacción

${ }^{16}$ La Cueva de Diktea se llama así por el Monte Dikté $(2.148 \mathrm{~m})$. Se encuentra al sur del pueblo de Psijró, situado al suroeste de la meseta de Lasiti (una corrupción de La Sitia, término de la época veneciana para denominar el extremo de la Creta oriental), y está a menos de 900 metros de altura. Según las diversas versiones mitológicas (la cueva alternativa es la del Monte Ida o Psiloritis, llamada Cueva de Idaean), allí nació el "padre de los dioses y los hombres". Por eso se la conoce también como la Gruta de Zeus. Tras ser descubierta por los habitantes de la región, fue explorada por el arqueólogo cretense Iosif Hatzidakis (1848-1936) y el italiano Federico Halbherr (1857-1930), y posteriormente por Arthur Evans y, entre 1899 y 1900, por su compatriota David George Hogarth (1862-1927). Éste último descubrió los rastros de un asentamiento humano desde el minoico medio hasta el periodo arcaico. En la Cueva del Monte Dikté, Zeus fue amamantado por las ninfas Adrastea e Ida, que lo alimentaron con la leche de la cabra Amaltea. Los nueve kuretes (guerreros divinos) custodiaban la cueva, haciendo ruido mientras bailaban alrededor de la entrada y golpeaban los escudos con sus lanzas, para que el salvaje Cronos no escuchara el llanto de la criatura. Ese fue el origen de las danzas guerrilleras cretenses.

${ }^{17}$ Tell El Amarna es el nombre árabe de una región situada en la ribera oriental del río Nilo, al norte de Asyut, célebre por ser el enclave donde se edificó la ciudad de Ajetatón ("Horizonte de Atón") a mediados del siglo XIV a. C. por orden del faraón Ajenatón que reinó entre 1353-1336 a. C. aproximadamente, periodo conocido como "amarniense".

${ }^{18}$ Henri "Hans" Frankfort (1897-1954), egiptólogo, arqueólogo y orientalista holandés. Entre 1925 y 1929 Frankfort fue director de las excavaciones de la Egypt Exploration Society (EES) de Londres en El-Amarna, Abydos y Armant.

${ }^{19}$ Cfr. Sue Hamilton, Ruth D. Whitehouse, Katherine I. Wright, David W.J. Gill et alii (2006), Archaeology and Women: Ancient and Modern Issues. London: Left Coast Press, p. 70. 
creto-egipcia también le facilitó contrastar la presencia de la civilización del Valle del Nilo en la isla mediterránea. Así nació su obra "Catálogo de objetos egipcios en el área egea" 20 .

John, romántico incurable, se enamoró perdidamente de Tell El Amarna, y las historias sobre Ajenatón y Nefertiti de la Dinastía XVIII de Egipto. Y aquí surge, inevitable, la leyenda del ojo izquierdo de la reina consorte del faraón hereje. ¿Por qué el busto de Nefertiti que puede ser admirado en el Neues Museum de Berlín no posee el ojo izquierdo? El enigma no tiene respuesta. Pero una de las pocas fotografías disponibles en la web de John Pendlebury, que también aparece en la sobrecubierta de la biografía realizada por la arqueóloga británica Imogen Grundon, es aquella donde se lo muestra con el torso desnudo y luciendo un collar faraónico digno de "La Mona Lisa de Amarna", con cuyo retrato escultórico (obra del escultor real Tutmosé) compartía la falta del mismo ojo.

El despliegue de John en Creta, sin embargo, fue mucho mayor que lo actuado en Egipto. En una sola campaña arqueológica en las montańas cretenses llegó a recorrer a pie más de mil seiscientos kilómetros ${ }^{21}$. "Un viaje es una alegría pura, ya sea acompañado por un robusto joven kurete del Dikté o por un viejo daktyl del Psiloritis, igualmente robusto; ya sea alojándose en casa del maestro de la aldea, en un monasterio, o en la desnuda ladera con los andrajosos gitanos. Haber estado en las cumbres del Psiloritis, en las cimas del Dikté y en el Afendes-Kavusi respirando el viento puro y penetrante, y haberse fatigado cruzando los calurosos vallecillos, con aquel inolvidable olor de hierbas, son experiencias cuyo recuerdo nada puede borrar» ${ }^{22}$.

En la década de 1930-39 John derrochó algo que le sobró durante toda su existencia, la energía; "pero una energía siempre bajo el control del pensamiento" 23 . En 1938 John trabajó con su compatriota Frank Thompson ${ }^{24}$ en Karfí25, en la meseta de Lasiti ${ }^{26}$. Thompson, como Pendlebury, se convertiría en héroe-mártir combatiendo con los guerrilleros comunistas búlgaros contra los nazifascistas.

${ }^{20}$ John Devitt Stringfellow Pendlebury (1930), Aegyptiaca: A Catalogue of Egyptian Objects in the Aegean Area. Cambridge: Cambridge University Press.

${ }^{21}$ Patrick Leigh Fermor (2003), Words of Mercury. London: John Murray Publishers, p. 186.

${ }^{22}$ J.D.S. Pendlebury: 1980, p. 13.

${ }^{23}$ S. R. K. Glanville, "J. D. S. Pendlebury", Journal of Egyptian Archaeology, London: Egypt Exploration Society, Vol. 28, Dec., 1942, pp. 61-63.

${ }^{24}$ El Mayor Frank Thompson (1920-1944). nacido en la India, estudió historia y arqueología en la Universidad de Oxford donde se hizo miembro del Partido Comunista del Reino Unido. En la 
La ciudad de Cnosós (a 5 km de Heraklión), capital de la isla según Homero, fue el centro floreciente de la civilización minoica. El abundante material descubierto durante las excavaciones confirmó esta teoría y permitió describir, o imaginar, la vida diaria de los minoicos. Por ejemplo, el "Acróbata", una figurilla de marfil que data de 1600 a. C. (exhibida en el Museo Arqueológico de Heraklión), representa a un atleta saltando por encima de un toro que no se ha conservado. Esta magnífica escultura fue descrita por John Pendlebury como "la más exquisita miniatura del mundo antiguo, incluido Egipto". Todo aquello estudiado e investigado lo volcaría en su obra cumbre que sería una introducción a la arqueología de Creta, con más de 700 yacimientos identificados ${ }^{27}$. Dedicado a su esposa Hilda, este trabajo es una exposición general de la cultura de Creta desde los tiempos más remotos hasta la época romana.

El 8 de febrero de 1933, John voló de Gaza (Palestina) a Bagdad (Irak) donde se encontró con su colega neerlandés "Hans" Frankfort. En la urbe a orillas del Tigris John exploraría los vestigios de la que fuera capital del Califato abásida. El viaje de retorno tuvo ribetes rocambolescos. John se subió al llamado "Ómnibus Nairn” 28 y cruzó el desierto de Bagdad a Damasco en un viaje de 880 kilómetros a través de una ruta no pavimentada. En la capital de los Omeyas recorrió museos, mezquitas y la tumba de Saladino. Seguidamente ingresó en el Líbano haciendo escalas en Baalbeck, Beirut, Biblos, Sidón y Tiro.

Segunda Guerra Mundial fue lanzado en paracaídas con otros tres comandos en Bulgaria donde se sumó a la resistencia antifascista. Herido y capturado, fue fusilado el 10 de junio de 1944 a la edad de 23 años. Su hermano más joven, Edward Palmer "E. P.” Thompson (1924-1993), fue historiador, escritor, militante socialista y activista por la paz.

${ }^{25}$ En 1934, John Pendlebury descubrió en el yacimiento arqueológico del monte Karfí un santuario y una tumba posminoicos. Estos descubrimientos revelaron que, tras el colapso de la talasocracia minoica, los habitantes de ciudades como Cnosós o Festos se refugiaron en los montes Karfí y Patela, cerca de Aguía Varvára.

${ }^{26}$ Cfr. Peter J. Conradi, A Very English Hero: The Making of Frank Thompson. London: Bloomsbury Publishing, p. 105.

${ }^{27}$ John D. S. Pendlebury (1939), The Archaeology of Crete: An Introduction. London: Methuen \& Co. Ltd.

${ }^{28}$ Desde 1923, dos hermanos neocelandeses combatientes durante la Primera Guerra Mundial en el Frente de Oriente Medio, Norman Nairn (1894-1968) y Gerald (1897-1980), operaron una compañía de transporte que disponía de unos buses estadounidenses marca Safeguard que transportaban 16 pasajeros por viaje recorriendo el trayecto en unas 20 horas. La Compañía Nairn estuvo en operaciones hasta la década de los años sesenta del pasado siglo. Véase James Stuart Tullett (1968), Nairn Bus to Baghdad: The Story of Gerald Nairn. Wellington (NZ): A.H. \& A.W. Reed; John M. Munro (1980), Nairn Way: Desert Bus to Baghdad. Delmar, New York: Caravan Books. 
Nuestro arqueólogo-viajero prosiguió luego hasta Palestina. En Jerusalén logró ingresar en los santuarios del Domo de la Roca y la Mezquita de Al-Aqsa. "John visitó a David Iliffe y su equipo en el museo de Jerusalén antes de dirigirse al castillo de los cruzados en Atlit ${ }^{30}$, al sur de Haifa, donde Hilary Waddington ${ }^{31} y$ su esposa tenían su base de operaciones. Desde Haifa, tomó el tren a Alejandría y zarpó a Atenas a reunirse con Hilda y David.»" ${ }^{32}$ Por entonces había sido publicado en Londres su libro-guía, "Manual del Palacio de Minos, Cnosós, con sus dependencias" 33 .

Mientras John trabajaba entre Cnosós y Tell El Amarna, Hilda daría a luz a sus dos herederos, un varón, David John Stringfellow Pendlebury (1932-1996), y una nińa, Joan Pendlebury (1934).

En un raro video de la web se puede ver a John en una triple función en Tell El Amarna: como arqueólogo, deportista y cómico ${ }^{34}$. La filmación está narrada entre otros por las egiptólogas Julia Samson ${ }^{35}$ y Margaret Drower ${ }^{36}$ que trabajaron allí con Pendlebury y fueron testigos de aquellas hazańas.

En 1935, John y Hilda alquilaron en Cambridge una casa a Arnold Walter Lawrence (1900-1991), hermano menor del legendario Thomas Edward Lawrence (1888-1935), el héroe británico de la Primera Guerra Mundial que

${ }^{29}$ David Iliffe, arqueólogo británico por entonces director del Museo de Jerusalén.

${ }^{30}$ El Castillo de Atlit, llamado originalmente Château Pèlerin ("Castillo del Peregrino"), se encuentra en la costa norte de Israel cerca de 13 kilómetros al sur de Haifa sobre la costa. Los Caballeros Templarios iniciaron su construcción en 1218 durante la Quinta Cruzada. Se trata de una de las fortalezas de los cruzados más importantes, que llegó a tener una guarnición de hasta 4.000 infantes y caballeros en estado de sitio. Fue conquistado por los musulmanes mamelucos bahríes liderados por el sultán turco de la etnia kipchaq Al-Malik al-Ashraf Salah al-Din Jalil Ibn Qalawún (ca. 1262 - 1293) en agosto de 1291, poco después de la caída del baluarte de Acre (28 de mayo). El castillo se mantuvo intacto durante cientos de ańos, hasta que fue dańado por el terremoto de Galilea de 1837. En los tiempos modernos, la fortaleza forma parte de un área de entrenamiento para comandos navales israelíes.

${ }^{31}$ Sir James Hilary Sheffield Waddington (1903-1989), arqueólogo, arquitecto y coleccionista británico.

${ }^{32}$ Imogen Grundon: 2007, p. 164.

33 J. D. S. Pendlebury (1933), Handbook to the Palace of Minos, Knossos, with its Dependencies. London: Macmillan \& Company.

${ }^{34}$ Egypt Exploration Society Excavations at Amarna Part 1: John Pendlebury http://www.ees. ac.uk/news/index/74.html

${ }^{35}$ Véase Margaret S. Drower (1985), Flinders Petrie: A Life in Archaeology. London: Victor Gollancz Ltd.

${ }^{36}$ Julia Samson (1985), Nefertiti and Cleopatra: Queen-Monarchs of Ancient Egypt. Norwich (UK): Rubicon Press. 
coincidía en muchos aspectos con la vida y la profesión de John Pendlebury. Es una paradoja que ese mismo año, en mayo, Lawrence de Arabia falleció en Dorset en un enigmático incidente con su moto.

\section{Amenaza de tormenta}

La última etapa de la vida de John sería la más gloriosa, la más heroica y la más trágica. Al estallar la Segunda Guerra Mundial y convertirse Grecia y el Egeo en una región de una importancia estratégica considerable, el conocimiento de Creta de John Pendlebury convenció al alto mando británico de que sus servicios resultarían indispensables en la contienda. El arqueólogo convertido en soldado recibió entrenamiento militar en la rama de caballería en Weedon (Northamptonshire) y fue enviado por el Servicio de Inteligencia para asistir a un curso de árabe en el Christ's College de la Universidad de Cambridge. Durante esta época de entusiasta preparación John estuvo junto a su amigo, colega y helenista Nick Hammond ${ }^{37}$. Éste, más tarde, junto a un amigo común, Thomas Dunbabin ${ }^{38}$, publicaría una biografía sobre las aventuras y desventuras de $\mathrm{John}^{39}$.

Finalmente John recibió los galones de capitán, siendo destinado al área de inteligencia militar en la zona de Creta. Por entonces, el alto mando británico para darle cobertura y autoridad le nombró vicecónsul en Heraklión. Según explica Dilys Powell ${ }^{40}$, se trataba del "vicecónsul más falso del mundo» ${ }^{41}$.

37 Nicholas Geoffrey Lemprière Hammond (1907-2001) ha sido probablemente la mayor autoridad en la historia antigua de Macedonia en el siglo XX. Fue estudiante de la Escuela Británica en Atenas y alumno del Clare College de Cambridge. Véase N. G. L. Hammond (1992), Alejandro Magno: Rey, general y estadista. Edición española de Adolfo J. Domínguez Monedero. Madrid: Alianza Editorial. Con el grado de teniente coronel, Hammond junto a Michael 'Mike' Cumberledge, un oficial de la Marina Real, operó un caique artillado, el HMS Dolphin, que protagonizó audaces incursiones en el Mediterráneo oriental y luego se destacó en la invasión de Creta en mayo de 1941.

38 Thomas James “Tom” Dunbabin (1911-1955), arqueólogo australiano de origen tasmanio. Con el rango de teniente coronel, Dunbabin colaboró en la organización de las guerrillas cretenses. Se lo conocía con el nombre en clave griego 'Guiánis'.

${ }^{39}$ Nicholas Hammond y Thomas James Dunbabin (1948), John Pendlebury in Crete: Comprising his Travelling hints and his First trip to Eastern Crete (1928) together with appreciations. Cambridge: Printed for private circulation at the University Press.

${ }^{40}$ Elizabeth Dilys Powell (1901-1995) fue una periodista, escritora y crítica de cine británica. Durante la Segunda Guerra Mundial se ocupó de difundir información acerca de la Resistencia Helénica contra los nazis. Escribió libros relacionados a películas y viajes especialmente sobre Grecia.

${ }^{41}$ Dilys Powell (1973), The Villa Ariadne. London: Hodder and Stoughton, p. 113. 
Durante la llamada drôle de guerre (guerra de broma) como la llamaban los franceses (ese periodo que va desde el 6 de octubre de 1939 al 10 de mayo de 1940, en el que británicos y franceses no intervinieron sino que prefirieron contemplar pasiva e hipócritamente como los nazis masacraban a los polacos), John fue uno de los pocos que tuvo la lucidez suficiente para anticipar el porvenir. Él estaba completamente seguro de que la Alemania de Hitler buscaba sojuzgar al mundo y que, para asegurarse el Mediterráneo oriental, iba a invadir a Grecia y Creta más tarde o más temprano. Y lo más revelador —algo que el propio alto mando británico no quiso creer hasta que ya era demasiado tarde-, Pendlebury creyó desde un primer momento que la invasión nazi iba a darse mediante el asalto de paracaidistas.

Esto lo corrobora Antony Beevor ${ }^{42}$, uno de los especialistas que certifica que "John Pendlebury, el arqueólogo, siempre estuvo convencido de que los alemanes invadirian Grecia y, después, su adorada Creta» ${ }^{43}$. Y luego agrega: "Pendlebury estaba decidido a quedarse en la isla para organizar la guerra de guerrillas. Se consideraba prácticamente un cretense»" ${ }^{44}$.

Pendlebury no se equivocó. Las Operaciones Marita (6 - 30 de abril de 1941) y Mercurio (20 de mayo - 1 de junio de 1941) se sucederían una tras otra y tanto Grecia como Creta quedarían sometidas al yugo nazi durante cuatro largos años.

La última vez que estarían juntos John y Hilda sería el 3 de junio de 1940. «La noche posterior a la salida de las últimas tropas británicas de las playas de Dunkerque, un hombre alto con un ojo de cristal se despedia de su mujer sobre la escalinata del Oxford and Cambridge Club. Era la vispera de su partida en hidroavión hacia Grecia. No volvieron a verse» ${ }^{45}$.

Desde su retorno a la isla, John comenzó a trabajar militarmente de cara a la invasión nazi con tres kapetanios ${ }^{46}$ cretenses: Manolis Banduvás, Guiorgos

42 Antony Beevor (1946) es un historiador y ex militar británico especializado en las batallas de la

Segunda Guerra Mundial (Stalingrado, Día D y Berlín) y la historia de la Guerra Civil española.

${ }^{43}$ Antony Beevor (2009), Creta: La batalla y la resistencia. Traducción: Santiago Jordán Sempere.

Barcelona: Crítica, p. 47.

${ }^{44}$ Antony Beevor: 2009, p. 146.

${ }^{45}$ Antony Beevor: 2009, p. 15.

${ }^{46}$ Los kapetanios eran los veteranos cretenses de las guerras contra los turcos a fines del siglo XIX. Eran caudillos populares y jefes de clanes que gozaban del mayor de los respetos. El paradigma del kapetanio es Miguel, el personaje central de la novela "Libertad o muerte" de Nikos Kazantzakis. 
Petrakoguiorguis y Andonis Grigorakis, este último conocido como 'Satanás'. Beevor dice que 'Satanás' era "el mejor jefe de todos”. Y luego agrega estas anécdotas: «Satanás —escribió Monty Woodhouse — ${ }^{47}$ debia su nombre a la creencia generalizada de que nadie sino el propio diablo puede sobrevivir a la cantidad de balas que llevaba dentro. [...] Otra de las caracteristicas que le distinguian era su mano mutilada. Enfadado consigo mismo tras perder mucho dinero jugando a los dados, pese a que habia prometido no volver jugar, se arrancó de un tiro el dedo con el que echaba los dados. En el acaloramiento del momento olvidó que el objeto pecador era al mismo tiempo el dedo con el que apretaba el pestillo de las armas»" ${ }^{48}$.

La localidad destinada al entrenamiento y cuartel de las fuerzas guerrilleras cretenses fue Krusonas ${ }^{49}$ y, en poco tiempo, los andartes (guerrilleros) recibieron el apodo de los 'krusoniotes', un sinónimo de levendes (en griego: 'valientes'). Estos partisanos serían identificados por la inteligencia militar alemana como "los matones de Pendlebury". ${ }^{50}$ "Esos guerrilleros o maquis, conocidos en Grecia con el nombre de 'andartes', formaban una banda aterradora. Hammond recuerda que "olian a sangre, carniceria y ajo en el mejor estilo cretense" ",

En las antípodas de la narración de Beevor, Lord Byron evoca a los andartes de antaño que, al igual que los cretenses, tuvieron que enfrentar al invasor más cruel y desalmado: "Envueltos en nuestro rudo capote albanés, tumbados sobre la tabla más dura de nuestro veloz bajel, o extendidos a la orilla de un rio, con la cabeza apoyada en las sillas de nuestros caballos, que nos servian de almohadas, siempre estábamos seguros de despertarnos frescos y dispuestos a las fatigas del día. [...] Unos han muerto ya; otros se hallan lejos; otros dispersos y aislados; otros, hoy rebeldes, recorren las montañas que coronan los valles del Epiro, pais donde la libertad deja oir todavia de vez en cuando el grito revolucionario de independencia y hace pagar con rios de sangre las crueldades de la tiranía... $»^{52}$.

Cuando arribaron las primeras tropas británicas a Creta, Harry Rudolph Fox Burr (fallecido en 1977), oficial de seguridad británico en Janiá, realizó un

${ }^{47}$ El coronel y diputado británico Christopher Montague "Monty" Woodhouse (1917-2001) en su autobiografía Something Ventured. London: Granada, 1982, p. 18.

${ }^{48}$ Antony Beevor: 009, p. 145.

${ }^{49}$ Krusonas se encuentra a $21 \mathrm{~km}$ al sudoeste de Heraklión, sobre la falda oriental del monte Psiloritis (Ida), en la altiplanie conocida como Nida, a 1500 metros de altura.

${ }^{50}$ Imogen Grundon: 2007, p. 249.

${ }^{51}$ Antony Beevor: 009, p. 146.

${ }^{52}$ Lord Byron, El sitio de Corinto. Colección Austral No 111. Madrid: Espasa-Calpe, 1976 (8a ed.), p. 101. 
testimonio muy elocuente sobre el espíritu militante de John Pendlebury: «Desde el primer momento de nuestro desembarco, su conocimiento de Creta y los cretenses fue inapreciable desde el punto de vista del personal superior y nuestro placer más humilde fue saber dónde y cómo comprar el mejor vino y los huevos más excelentes... Sus buenos amigos estaban en todas partes y andar junto a él era algo así como disfrutar de una bacanal de la hospitalidad cretense. Su amor por la isla parecía ser la gran pasión de su vida y él hizo que todos la compartieran» ${ }^{53}$.

Jacinto Antón ${ }^{54}$ confiesa en un reportaje hecho a Patrick Leigh Fermor ${ }^{55}$ : " ¿Cómo era Pendlebury?, le pregunté, tras recordar ambos nuestro encuentro en Londres hace dos años y asegurarle yo, para su satisfacción, que seguía perseverando en la lectura de Horacio. "Muy alto y de aspecto muy saludable, atractivo. Aquel dia iba de uniforme, pero con un rifle en bandolera y una canana llena de cartuchos a la manera de un kapetanios, un jefe de la guerrilla cretense. No pude dejar de fijarme en su célebre ojo de cristal, que se decía solía dejar sobre la mesa de su despacho para indicar que volvería pronto. Llevaba en la mano el famoso bastón estoque. $Y$ cuando alguien le pidió que lo mostrara, sacó la hoja de la vaina con un único giro de la muñeca y trazó un relámpago letal mientras exhibia una gran sonrisa”. ¡Qué diablo de hombre debia ser Pendlebury para despertar la admiración de alguien como Leigh Fermor! A raíz de lo del bastón estoque, que Pendlebury consideraba el arma ideal contra los paracaidistas, hablamos de esgrima. "No creo que él la practicara deportivamente, pero, claro, como sabe, habia recibido entrenamiento de caballería en Weedon antes de ser nombrado capitán de inteligencia militar y enviado de vuelta a Creta para organizar la defensa de la isla con los irregulares [usó esta deliciosa palabra] bajo la tapadera de su puesto de vicecónsul en Heraklion". Leigh Fermor

${ }^{53}$ Imogen Grundon: 2007, p. 256.

${ }^{54}$ Jacinto Antón (Barcelona, 1957) es un periodista español que lleva más de 20 años en la sección de Cultura del diario El País de Madrid.

${ }^{55}$ Patrick Leigh Fermor (1915-2011), arquetipo del viajero británico, en 1933 cruzó Europa a pie, de Londres a Estambul. En 1942, con el grado de mayor llegó a Creta en paracaídas. Allí, disfrazado de pastor, en coordinación con la resistencia y con la ayuda del capitán Bill Stanley Moss (19211965), logró secuestrar al general Heinrich Kreipe (1895-1976), comandante alemán de la isla, y trasladarlo a Egipto. El célebre episodio fue llevado al cine a través de la película Ill Met by Moonlight (Emboscada en la noche) en 1957. Desde el fin de la guerra, vivió en Kardamyli, en el Peloponeso, en una casa diseñada por él mismo. En 2007 fue nombrado Caballero de la Orden del Fénix por el gobierno griego. Autor de libros como Mani: Viajes por el sur del Peloponeso. Traducción del inglés de Agustina Luengo. (Barcelona: Acantilado, 2010), y Roumeli: Viajes por el norte de Grecia. Traducción: Dolores Payás. (Barcelona: Acantilado, 2011). 
estornudó y me pareció notar a través de la línea que le abrumaba súbitamente el peso de tantas aventuras y tanta vida. "1,56

\section{Lawrence de Creta}

A partir del 6 de febrero de 1941, cuando el mariscal de campo Erwin Rommel quedó a cargo del Afrika Korps y de las operaciones alemanas contra Egipto y el Canal de Suez, y al postergarse indefinidamente la llamada Operación Herkules $^{57}$, Creta se convirtió en el trampolín indispensable que necesitaban los nazis para abastecer a las fuerzas acorazadas del "Zorro del Desierto".

Coincidentemente, y previendo esta amenaza, a fines de marzo de 1941, John Pendlebury realizó una minuciosa recorrida por puestos de observación y baluartes guerrilleros en las montańas y altiplanicies de Creta occidental, desde Heraklión a Hierápetra, en la costa sudeste, y luego volvió hacia el norte a través del macizo central hasta la meseta Nida y el monte Psiloritis ${ }^{58}$.

Saltaba a la vista que la única forma de apoderarse de la mítica isla del rey Minos era mediante un asalto de paracaidistas. La Real Fuerza Aérea era inexistente en el Mediterráneo oriental, ya que la gran mayoría de sus aparatos disponibles estaban exclusivamente destinados a la defensa del país del Nilo. En cambio, la Marina Real tenía una fuerte presencia en la región. Las fuerzas navales del Eje representadas por Italia habían sufrido un golpe devastador en la Batalla del Cabo Matapán, la punta central del tridente en que acaba el Peloponeso (Laconía), en el sur de Grecia, y habían quedado fuera de combate. Allí los británicos, entre el 27 y el 28 de marzo de 1941, hundieron tres cruceros pesados y dos destructores italianos (con un total de 2.303 muertos), averiando seriamente al acorazado Vittorio Veneto, y sufriendo apenas la pérdida de un avión torpedero.

El ideólogo del asalto aéreo sobre Creta fue Kurt Arthur Benno Student (1890-1978), general de la Luftwaffe que estaba a cargo de los Fallschirmjäger (cazadores paracaidistas), conocidos como los “diablos verdes". Estos comandos

${ }^{56}$ Jacinto Antón, “El arrojado Lawrence de Creta. John Pendlebury, arqueólogo y soldado: El ojo de cristal y las pesadillas de Hitler”, El País, Madrid, 3 de agosto de 2003.

${ }^{57}$ El plan ítalo-germano para conquistar la isla de Malta y tener el campo libre para el abastecimiento del Afrika Korps en Libia y Egipto.

58 Wes Davis (2013), The Ariadne Objective: The Underground War to Rescue Crete from the Nazis. New York: Crown Publishers, pp. 44-45. 
eran seleccionados, muy entrenados y bien equipados. Para el conjunto de las operaciones, el general Student contaba con 22.750 hombres y más de 1200 aviones entre bombarderos, cazas, transportes y planeadores. El 25 de abril de 1941 un Hitler exultante ordenó: "Sprung nach Kreta!” (Salto hacia Creta).

La defensa de la isla, la llamada "Creforce", estaba a cargo del general de división inglés Sir Bernard Cyril Freyberg (1889-1963) que contaba con unos 25.000 hombres entre británicos, australianos y neozelandeses - ANZAC $^{59}$ así como 9.000 griegos de la 5. ${ }^{\mathrm{a}}$ División «Kríti» y los restos de la 12. ${ }^{\mathrm{a}}$ y 20. ${ }^{\mathrm{a}}$ Divisiones de Infantería griega. A éstos había que sumarles unos 6.000 guerrilleros cretenses muy motivados que nunca serían convocados por el mando británico.

A la operación denominada Mercurio (Merkur) — nombre del dios alado romano (el Hermes de la mitología griega) — se le puso como fecha de inicio, en principio, el domingo 18 de mayo de 1941; pero luego se postergó para el martes 20 de mayo.

En mayo de 1941, durante diez días, tuvo lugar uno de los choques más sangrientos de la Segunda Guerra Mundial: la Batalla de Creta, la primera gran operación militar aerotransportada de la historia.

A las 06.00 de la mañana del día susodicho - los 150 Stukas de vuelo rasante, 280 bombarderos (Dornier, Heinkel) y 200 cazas (principalmente Messerschmitt Bf 109E y Bf 110E) del VIII cuerpo aéreo de la Luftwaffe que sobrevolarían Creta - comenzó el bombardeo de los aeropuertos de Máleme y Heraklión. Cuando llegó el salto de las primeras oleadas de paracaidistas desde los trimotores Junkers JU 52 se produjo la gran sorpresa. A la mayoría de los temibles Fallschirmjäger que consiguieron llegar al suelo en los cuatro puntos de descenso (Máleme, Bahía de Suda, Rétimnon y Heraklión), los capturaron o los mataron, antes de que pudieran conseguir las armas de los contenedores que se habían esparcido fuera de su alcance. Unas veces los británicos y los ANZAC, y otras los cretenses, armados éstos con viejas escopetas, hachas y cuchillos, y hasta con piedras y botellas rotas, acabaron con todos los paracaidistas.

Daniel Marcus (Dan) Davin (1913-1990), oficial de inteligencia neozelandés, profesor de las Universidades de Otago y Oxford, que escribió la historia militar de los ANZAC en Grecia y Creta y fue testigo de la invasión en la que sería

\footnotetext{
${ }^{59}$ Acrónimo de Australian and New Zealand Army Corps.
} 
herido, aseguró que durante el primer día del ataque los paracaidistas estaban indefensos en el aire mientras caían y "era como cazar patos"60. Pero miles de paracaidistas seguían cayendo desde el cielo y con la llegada de una división de los Gebirgsjäger (cazadores montañeses) comenzó a correr la cuenta regresiva para el fin de la libertad y la independencia de Creta.

A pesar de su considerable ventaja numérica (más de 40 mil británicos y griegos contra 22 mil alemanes), y sus bien atrincheradas posiciones defensivas, el general Freyberg ${ }^{61}$ no era precisamente la persona adecuada para tal momento y lugar. Carente de estrategia y una coordinación sincronizada, siempre subestimó y desoyó las advertencias y consejos de John Pendlebury respecto de confiar en el pueblo cretense, armarlo como correspondía y disponer de las unidades guerrilleras para cerrar brechas e infiltraciones.

Freyberg descartó una y otra vez los informes de inteligencia respecto a un asalto de paracaidistas, imaginando que la invasión nazi se produciría mediante un desembarco anfibio. Su negligencia sería fatal y la Batalla de Creta se perdería por su culpa como lo demuestra el estudio académico del mayor Kelsey A. Smith del Cuerpo de Infantería de Marina de EE.UU ${ }^{62}$. Lo mismo asegura una página web de estudios históricos de Nueva Zelanda ${ }^{63}$. "El general Freyberg, acusado por muchos, de una inadecuada dirección de las operaciones, realizó otra de sus muchas maniobras injustificadas, al ordenar al $23^{\circ}$ Batallón [Infantería de Nueva Zelanda] que se retirase de Janiá» ${ }^{64}$.

${ }^{60}$ Dan Marcus Davin (1953), Crete. Wellington, N.Z.: War History Branch, Dept. of Internal Affairs, p. 33.

${ }^{61}$ Freyberg fue parte de una decena de generales de salón apadrinados por Winston S. Churchill. Otro integrante de esta camada fue el tristemente célebre teniente general Arthur Ernest Percival (1887-1966) que rindió vergonzosamente la plaza fuerte de Singapur (15 de febrero de 1942). Allí sus 85 mil hombres capitularon sin condiciones ante los 36 mil soldados del general japonés Tomoyuki Yamashita luego de una desastrosa retirada a lo largo de la Península de Malaca. Sin embargo, el más rotundo fracaso de Churchill en la Segunda Guerra Mundial fue su decisión de colocar en manos del mediocre mariscal de campo Bernard Law 'Monty' Montgomery (1887-1976) la Operación "Market Garden” (17 al 25 de septiembre de 1944) que fue la segunda gran operación aerotransportada de la historia. Su falta de interés por la seguridad de sus tropas y el desprecio por los informes de la Inteligencia acabaron con cerca de veinte mil hombres (británicos, polacos y estadounidenses) y dieciocho mil civiles holandeses que perecieron de inanición.

${ }^{62}$ Major Kelsey Aaron Smith (2008), The Balance Sheet of the Battle of Crete: How Allied Indecision, Bureaucracy, and Pretentiousness Lost the Battle. Ann Arbor, Michigan: Nimble Books. (71 pp.).

${ }^{63} \mathrm{http} / /$ www.nzhistory.net.nz/war/the-battle-for-crete/the-controversies

${ }^{64}$ José Antonio Alcaide Yebra (2008), Unternehmen "Merkur»: La conquista de Creta, 1941. Valladolid: AF Editores, p. 82. 
Los nazis se quedarían en la isla hasta 1945 cometiendo todo tipo de depredaciones y crímenes de guerra. Eso sí, no tendrían un solo segundo de respiro. Los guerrilleros cretenses los tendrían en la mira las 24 horas del día y no les darían ni tregua ni cuartel ${ }^{65}$.

Al cumplirse el $60^{\circ}$ aniversario de la Batalla de Creta en el 2001, Patrick Leigh Fermor en un discurso en Cnosós dijo que Pendlebury “... proféticamente anticipó la realidad que se plasmaría meses más tarde, sobre que los veteranos de Creta de las antiguas guerras contra los turcos serían vitales para la eventual defensa de la isla. Estos kapetanios regionales, jefes naturales —como Satanás, Banduvás y Petrakoguiorguis, y muchos otros, con sus bigotes amplios y botas altas - tenían muchas virtudes y algunos, tal vez, algunos falencias, pero todos ellos eran líderes natos. Todos eran valientes, amaban a su país con pasión y reconocieron esas mismas cualidades en Pendlebury"66.

\section{I... como Ícaro ${ }^{67}$}

El miércoles 21 de mayo por la tarde, al comprobar que el tercer batallón del primer regimiento de paracaidistas al mando del experimentado mayor KarlLothar Schulz (1907-1972) estaba a punto de apoderarse de Heraklión, John supo que había llegado el momento de replegarse hacia Krusonas para organizar desde allí la resistencia. Salió en automóvil por la puerta occidental, la de Janiá, que forma parte de las antiguas fortificaciones venecianas. "Pendlebury, armado con su fusil y, según la mayoría de las versiones, vestido con uniforme, salió de la ciudad por la puerta Canea... Iba acompañado por su conductor y un pequeño grupo dirigido por Satanás, el capitán de la guerrilla de Krusonas. [...] Casi de inmediato se toparon con una sección de alemanes en Kaminia, a menos de un kilómetro de las murallas de la ciudad. En la lucha que estalló, se dice que Pendlebury mató a tres enemigos antes de ser alcanzado en la parte superior del pecho. Los alemanes lo llevaron, sangrando profusamente, a una casa que habia del otro lado de la carretera, y lo dejaron al cuidado de dos mujeres. Esa noche llegó un doctor alemán y le restañó las heridas. El día siguiente, 22 de mayo, otro grupo de paracaidistas llegó a la casa.

${ }^{65}$ Véase Ricardo H. Elía, "La resistencia cretense a la invasión nazi (1941-1945)", Grecia Ayer y Hoy, Actas del Segundo Congreso de Estudios Griegos, 12-14 Octubre de 2011. Santiago: Facultad de Filosofía y Humanidades, Universidad de Chile, 2013, pp. 127-138.

${ }^{66}$ Patrick Leigh Fermor, "John Pendlebury and the Battle of Crete", The Spectator, London, 20th October 2001, p. 65.

${ }^{67}$ Quisimos evocar la aleccionadora película de 1979 del director francés Henri Verneuil protagonizada por Yves Montand. 
[...] Se llevaron a las dos mujeres a un campamento provisional y arrastraron a Pendlebury fuera de la casa, lo reclinaron contra una pared y lo fusilaron $"$.

Todos los testigos e investigadores concuerdan que la razón del fusilamiento fue que John estaba vestido con ropas cretenses. Según Aristea, una de las dos hermanas de apellido Drossoulakis (la otra se llamaba Theonymphe) que lo atendieron, John vestía la indumentaria típica debido a que su uniforme estaba empapado de sangre.

Ícaro en su vuelo pasó tan cerca del sol que la cera que sostenía sus alas pegadas al cuerpo se derritió y cayó al mar. Si consideramos el sol como símbolo de la verdad, Ícaro se acercó tanto a la verdad que pagó este atrevimiento con su vida. Pendlebury había adivinado el asalto paracaidista nazi. Y como Ícaro, debió amortizar tanta lucidez y sagacidad con su propia vida.

Es común que ante la talla de personajes como Pendlebury, surjan leyendas y se fragüen anécdotas que pertenecen a la dimensión mítica. Así se dice, sin pruebas o fuentes serias, que Hitler no descansó de una de sus habituales paranoias, hasta que tuvo encima de su escritorio el ojo de cristal de John Pendlebury. En realidad se trataba de rumores esparcidos por los propios montańeses cretenses partidarios del héroe mártir ${ }^{69}$. Lo que está comprobado es que los alemanes desenterraron su cuerpo y lo examinaron minuciosamente. Hasta se tomaron la molestia de arrancarle jirones de su camisa para demostrar que usaba ropas civiles y así justificar el asesinato. Sin embargo, la ola de masacres de civiles cometidas por los enfurecidos paracaidistas en distintas localidades cretenses, a partir del 1 de junio de 1941, ha demostrado que en realidad las fuerzas nazis no pudieron tolerar que milicianos pobremente armados los vencieran en los combates cuerpo a cuerpo. A partir del 23 de mayo se decretó que por cada soldado alemán abatido por irregulares murieran diez civiles cretenses ${ }^{70}$. Así se sucedieron las matanzas como la de la aldea de Kondomarí, que fue registrada fotográficamente en los archivos alemanes $^{71}$, y la destrucción de Kandanos ${ }^{72}$.

${ }^{68}$ Antony Beevor: 2009, p. 205.

${ }^{69}$ Imogen Grundon: 2007, p. xii.

${ }^{70}$ Cfr. Miguel del Rey y Carlos Canales (2012), Fallschirmjäger: Paracaidistas 1935-1945. Madrid: Editorial Edaf, p. 121.

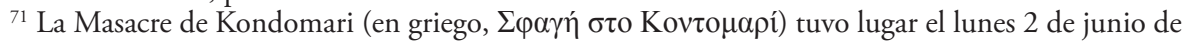
1941. La aldea de Kondomarí fue ocupada por los paracaidistas nazis que se ensańaron con la población a la que hicieron responsable de las bajas sufridas frente a los guerrilleros cretenses. Por 
Para los nazis la conquista de Creta fue una victoria pírrica. Tuvieron 3.986 muertos (de los cuales 3.094 eran paracaidistas) y 2.594 heridos. Perdieron 350 aviones, de ellos 151 Junkers 52 de metal acanalado modelo 3/mg3e, y murieron 312 aviadores. Ante este balance, Hitler no volvió a permitir otra operación aerotransportada durante el resto de la guerra. Student bien pudo haber dicho como Pirro, el basileos de Epiro, Macedonia y Sicilia, luego de la batalla de Ásculo (279 a. C.) contra los romanos: "Otra victoria como ésta y estamos perdidos". Como corolario, el general de la Luftwaffe admitió que Creta fue "la tumba de los paracaidistas alemanes". Por entonces, los agentes del servicio de inteligencia de las $\mathrm{SS}^{73}$ usaban el apodo 'Der kretische Lawrence' (El Lawrence cretense) para referirse a John Pendlebury ${ }^{74}$.

\section{El héroe nunca muere}

La leyenda de un héroe tuerto liderando las guerrillas cretenses siguió despertando la tribulación durante meses de alemanes y británicos. "El mito de Pendlebury era tan intenso que el comandante de brigada Shearer ${ }^{75}$, jefe de la inteligencia militar en El Cairo, informó a Churchill el 28 de agosto, tres meses después del fin de la batalla; "También tratamos de lanzar con paracaidas un equipo de radiotransmisión a Pendlebury, quien está controlando en gran medida las actividades de la guerrilla en las colinas cretenses". ${ }^{76}$.

lo menos sesenta civiles fueron fusilados por los paracaidistas. Las escalofriantes escenas fueron registradas por Franz Peter Weixler (1899-1977), un fotógrafo militar alemán (Bundesarchiv). El jefe ejecutor fue el teniente Horst Trebes (1916-1944), pero el verdadero responsable fue el general de la Luftwaffe Kurt Student que fue sobreseído inexplicablemente por un tribunal británico que los juzgó después de la guerra por éste y otros crímenes de lesa humanidad

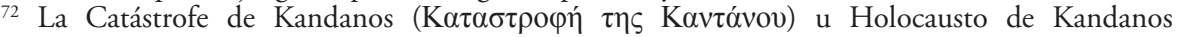

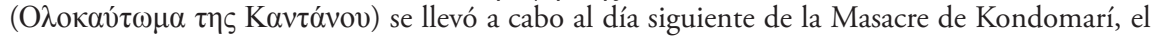
martes 3 de junio de 1941. El mismo ejecutor, Trebes, hizo asesinar a 180 residentes y todas las casas de la aldea fueron incendiadas y demolidas como escarmiento contra la población por haber ayudado a la resistencia cretense en los días previos. Las masacres de los nazis contra las poblaciones cretenses continuarían con igual o peor saña. Alikianós, Furnes, Anoguía, Rodakino y Kalicrati, son algunas de esas localidades devastadas donde hombres, mujeres, ancianos y niños fueron masacrados por hombres de negro sin corazón.

${ }^{73}$ El Sicherheitsdienst des Reichsführers-SS (SD), era el Servicio de Seguridad de las SS (Schutzstaffel o 'escuadras de defensa') y del Partido Nazi, y dependía de la Reichssicherheitshauptamt (RSHA), es decir, la Oficina Central de Seguridad del Reich en Berlín.

${ }^{74}$ Imogen Grundon:2007, p. xii.

${ }^{75}$ Eric J. Shearer. Véase John W. Gordon (1987), The Other Desert War: British Special Forces in North Africa, 1940-1943. Westport, Connecticut: Praeger, p. 49.

${ }^{76}$ Antony Beevor: 009, p. 206. 
Hoy día, los restos de John Pendlebury descansan en una tumba del cementerio militar británico de la bahía de Suda (al sudeste de Janiá, Creta). En su lápida puede leerse "Capitán J. D. S. Pendlebury, 22 de mayo de 1941, 36 años de edad", y un epitafio que es un verso de "Adonais", la Elegía de Percy Bysshe Shelley (1792-1822) por la muerte de su amigo, John Keats (1795-1821): He has outsoared the shadow of our night ${ }^{77}$. La clave de este pasaje del poema está en el párrafo siguiente:

"Envy and calumny and hate and pain, And that unrest which men miscall delight,

Can touch him not and torture not again;

From the contagion of the world's slow stain

He is secure, and now can never mourn

A heart grown cold, a head grown gray in vain;

Nor, when the spirit's self has ceased to burn,

With sparkles ashes load an unlamented urn» ${ }^{78}$

Jacinto Antón celebra las hazañas del héroe: "Educado en Cambridge, egiptólogo, helenista, campeón deportivo, luchador contra los nazis, Pendlebury es un gran personaje romántico" ${ }^{79}$.

Por su parte, Robert Twigger ${ }^{80}$ ironiza en un artículo del Daily Mail: «En una época en que enanos como Beckham y Blair son nuestros representantes internacionales,

77 "Él se ha elevado sobre la penumbra de nuestra noche."

78 «El odio y la calumnia,/El dolor y la envidia,/ Y esa angustia que el hombre llama dicha,/ Ya no podrán volver a torturarle,/Está, por fin, a salvo de que el mundo/Le contagie su mancha corrosiva,/Y ya no ha de sufrir, si reina el frío/En otro corazón,/o si encanece,/ En vano,/ otra cabeza,/Ni llenará de estériles cenizas/Cuando deje de arder dentro del alma/La llama que la habita,/La urna por quien nadie se conduele.» - Adonais. Elegía de Percy B. Shelley (1944). Traducida por Julio A. Roca (1873-1942). Córdoba, Argentina: Edición de la Asociación Argentina de Cultura Británica de Córdoba - Peuser, pp. 106-107.

${ }^{79}$ Jacinto Antón: 2003.

${ }^{80}$ Robert Twigger (nacido en 1965), escritor británico educado en el Balliol College de la Universidad de Oxford. Polímata, es político, filósofo, poeta y cineasta. Dos de sus libros son Lost Oasis: A Desert Adventure: In Search Of Paradise (2007), una aventura del desierto modelada en exploradores como el conde y aviador húngaro László Almásy (1895-1951), personaje que inspiró el argumento de la película 'El paciente inglés' (1996); y Red Nile: The Biography of the World's Greatest River (2013). Actualmente vive en El Cairo, Egipto. 
se me hizo extraño y desvergonzadamente orgulloso leer sobre la vida y los logros reales del "Lawrence de Creta", el capitán John Pendlebury»".

Un autor anónimo y visionario escribió: "Le quitaron su vida, sí, pero no su historia. Todavia las madres de Creta, cuando sus hijos no pueden dormir, les cuentan que una vez, en un reino muy lejano, un caballero llamado John Pendlebury prometió que velaria por la libertad, que fue a Creta para estudiar sus históricas ruinas y que, cuando llegó su hora, luchó valientemente contra todos los malvados que asediaban la isla. También que está enterrado en la bahía de Suda, al borde del mar, donde su alma no descansa del todo, pues uno de sus ojos siempre vigila para que los malvados no vuelvan nunca a molestar a los niños cretenses, que deben crecer felices y en paz» ${ }^{82}$.

Querido John, gracias por seguir viviendo entre los amantes de Grecia y los defensores de Creta. Siempre estarás presente en nuestros corazones.

Cuando vayas a Creta, cretense, saluda por mi a Creta, saluda en mi nombre a la montaña, el viejo Psiloritis ${ }^{83}$.

${ }^{81} \mathrm{http} / / /$ www.dailymail.co.uk/home/books/article-463039/Bring-glass-eye-Cretan-Lawrence.html

82 "¿Pendlebury? Por supuesto" http://queganelpeor.blogspot.com.ar/2013/03/pendlebury-porsupuesto.html

83 “El cretense exilado". Una 'Mantinada' del Psiloritis. Citado en J.D.S. Pendlebury:1980, p. 13. La Mantinada (en griego: $\mu \alpha v \tau \imath v \alpha ́ \delta \alpha$, pl. $\mu \alpha v \tau \imath v \alpha ́ \delta \varepsilon \varsigma$ ) es una recitación popular en Creta que tiene un ritmo particular que siempre recibe el acompañamiento de la lira y el laúto (laúd). Tiene verso decapentasílabo y a menudo es antifonal. El término deriva del veneciano matinada (canción de la mañana). 